\title{
O uso de mídias sociais pelo Sport Club Corinthians Paulista
}

\author{
Marcio Noveli ${ }^{1}$ \\ Carlos Cézar Montagnini Costa ${ }^{2}$
}

\section{Resumo}

$\mathrm{Na}$ interação com seus torcedores, times de futebol tem utilizado redes sociais. Nessse sentido, esse estudo teve como objetivo descrever a utilização das redes sociais no relacionamento do Sport Clube Corinthians Paulista com seus torcedores e o modo como os torcedores lidam com o clube nas redes sociais. Estruturou-se um estudo de caso de abordagem descritiva e método misto, com aplicação de questionário com os torcedores e entrevista com o gerente de conteúdo digital do clube. Por meio de estatística descritiva e análise temática, levantou-se que tanto o clube quanto os torcedores priorizam a utilização da rede social Facebook, apesar de, aparentemente, não alcançar a extensão de faixa etária pretendida. Também se identificou que apesar de o clube e os torcedores elencaram o Twitter como a segunda rede mais importante na sua interação, ela é preterida e é a menos utilizadas em relação a outras mídias sociais. E que os torcedores destacam que, apesar de o clube estar muito presente nas redes sociais, interage pouco com o torcedor. Esses resultados refletem a necessidade de adequação das redes sociais à gestão do relacionamento com os clientes.

Palavras-chave: Interação com os Clientes. CRM. Redes Sociais.

\begin{abstract}
In interacting with their supporters, soccer teams have been using social networks. This study aimed to describe the use of social networks of Sport Clube Corinthians Paulista in its interaction with its supporters and how they relate with the team in social networks. A case study of a descriptive approach and mixed method was developed, with questionnaire application with the supporters and interview with the digital content manager of the club. By means of descriptive statistics and thematic analysis, it was pointed out that both the club and the fans prioritize the use of the social network Facebook, although, apparently, it does not reach the desired age range. It has also been identified that although the club and fans have branded Twitter as the second most important network in their interaction, it is deferred and is less used in relation to other social media. And that, although the club is very present in the social networks, it interacts little with the fan. These results reflect the need to adapt social networks to customer relationship management.
\end{abstract}

Key words: Clients interaction. CRM. Social Networks.

\section{INTRODUÇÃO}

\footnotetext{
${ }^{1}$ Doutor em Administração de Empresas pela Fundação Getúlio Vargas-SP. Professor da Universidade Estadual de Maringá. Marcionoveli@yahoo.com.br

${ }^{2}$ Carlos Cézar Montagnini Costa. Montagnini.representacao@gmail.com
} 
Por um lado, as empresas e organizações devem estar receptivas e abertas, criando canais de comunicação com a sociedade e prestando contas a ela. Precisam focar seu público estratégico, considerando que, indiretamente, também podem atingir um público que atualmente não é o foco, podendo vir a tornar-se em um futuro próximo. Por outro, a comunicação digital e seus conteúdos, que se passam exclusivamente em ambientes tecnológicos utilizando ferramentas colaborativas, promovem trocas, interações e relações de sociabilidade dentro de um contexto social existente. (TERRA, 2011)

No ponto de intersecção entre essas duas linhas, as redes sociais são novos canais de comunicação entre o clube e seus torcedores, conexão que era limitada às emissoras de televisão através de programas esportivos.

Atualmente, o torcedor tem acesso às páginas oficiais do clube em diversas redes sociais, tais como Instagram, Twitter, Facebook e YouTube, o que possibilita a interação entre as partes, mesmo estando muitas vezes a quilômetros de distância da sede, o torcedor pode dar sua opinião, elogiando ou criticando as atuações, contratações e comunicações do time.

Ações digitais beneficiam os torcedores, que podem se sentir mais próximos do clube e, supostamente, o clube pode medir se os investimentos nessas mídias são perceptíveis aos torcedores. Diante do contexto, pode-se levantar o seguinte questionamento: Como o Sport Club Corinthians Paulista (SCCP) utiliza os canais de mídias sociais no estreitamento do relacionamento com seus torcedores?

Para essa pesquisa, foi proposto como objetivo geral: descrever como as ferramentas de Mídias Sociais, baseadas em Tecnologia da Informação e Comunicação (TIC), tem viabilizado o estreitamento do relacionamento entre o Sport Club Corinthians Paulista e seus torcedores. E, para isso, o estudo pautou-se em uma abordagem descritiva, qualitativa e quantitativa, trazendo como estratégia de pesquisa um estudo de caso, a qual utilizou, entrevista e questionários para o alcance dos objetivos.

Lenvantou-se que a principal rede social utilizada, de maneira geral e para interação, tanto pelos torcedores pesquisados quanto pelo SCCP é o Facebook, por meio do qual o clube se dedica nas postagens que promovem sua marca, realizam promoções, divulgam informações e interagem com o público, e por meio do qual o público interage com o clube. $\mathrm{O}$ clube também prioriza sua presença no Twitter, por onde interage mais dinamicamente com seus torcedores. Considerada também, como o segundo meio de interação mais usado pelos respondentes. E também se identificou que que a participação do público nas redes sociais em que o SCCP está presente é frequente, motivada principalmente por amor e fanatismo. 
Observou-se, ao final, que as redes sociais utilizadas pelo clube têm um bom alinhamento com as utilizadas com o público, apesar de poderem ser melhor adequadas. E que, apesar de as redes sociais serem consideradas importantes para a divulgação e fortalecimento da marca do clube, visto a intensa atividade gerada no ambiente virtual, e consideradas um importante canal de interação pelos torcedores, os torcedores consideram que as informações fornecidas pelo clube, na sua interação, são insuficientes.

\section{TECNOLOGIAS PARA GESTÃO DO RELACIONAMENTO COM O CLIENTE}

As Tecnologias de Informação e Comunicação (TICs) tiveram seus primeiros passos em 1920, quando a Associated Press, pioneira na utilização das telecomunicações, passou a enviar notícias através de 165 mil quilômetros de fios nos Estados Unidos e quase 16 mil quilômetros de cabos através do oceano. (STAIR; REYNOLDS, 2011). E se resumem ao conjunto de todo software e todo hardware que uma empresa necessita para alcançar seus objetivos. (LAUDON; LAUDON, 2010).

O hardware consiste em um equipamento físico do computador, designado para operar atividades como entrada, processamento e saída de dados ou informações, enquanto software consiste em programas que coordenam e direcionam as operações do computador, responsáveis por permitirem que o computador processe os dados e os transforme em informações. (STAIR; REYNOLDS, 2011).

As TICs proporcionam a coleta, armazenagem, transparência, apresentação e acesso aos dados, informações e conhecimentos, combinando hardware com software. (URDAN; URDAN (2010). A informação como dados processados, que podem ser fatos, valores, observações e medidas ainda não processadas ou organizadas é a interpretação, é o dado filtrado analisado e resumido, podendo ser utilizada pelas organizações como um recurso, como um ativo ou como um produto. (GORDON; GORDON, 2011).

Sendo a informação utilizada como recurso, ativo ou produto, pode-se identificar o grau de importância para as organizações em conseguir identifica-la e categorizá-la para obter vantagem competitiva. Se não houver um encaminhamento correto para as informações, ou seja, um receptor preparado para utilizá-la, tal informação torna-se apenas dados novamente. E diagnosticar necessidades de informação, realizar avaliação sobre a tecnologia da informação que atenda às necessidades e enfim projetar os sistemas de informações que sejam 
adequados, formam a base do desempenho efetivo na atualidade. (GORDON; GORDON, 2011).

É de suma importância que as TICs sejam utilizadas nas organizações, para que exista uma vitalidade e chances de competir em um mercado cada vez mais concorrido e com acesso facilitado à dados, graças à internet. Segundo Gordon e Gordon (2011), as TICs permitiram que, de maneira eficaz, pessoas, grupos e organizações, fizessem a gestão de suas informações, consequentemente tais avanços permitiram que, com um custo relativamente baixo, quantidades enormes de informações sejam processadas e acessadas. E as TICs viablizam Sistemas de Informação (SI), que são ferramentas utilizadas para gestão de um negócio e facilitação da análise dos dados.

Utilizando dos recursos de SIs, as organizações começam a explorar as mídias sociais e suas tecnologias, para transformar os dados coletados naquele espaço em informações, e estreitar o relacionamento com seu cliente, pensando não somente na estratégia de curto prazo, mas também em estratégias de longo prazo.

Especifiamente na gestão do relacionamento com o cliente, tem-se os sistemas denominados CRM (Customer Relationship Management), que auxiliam nesse processo. A gestão de relacionamento com cliente pode ser considerada como uma filosofia, que orienta a organização a ter como foco principal o cliente. (GORDON; GORDON, 2011). Nesse mesmo sentido, mas de maneira específica, pode ser considerada "uma abordagem empresarial destinada a entender e influenciar o comportamento dos clientes, por meio de comunicações significativas para melhorar as compras, a retenção a lealdade e a lucratividade deles". (SWIFT, 2001, p.12).

O software de CRM é um sistema exatamente para que esse objetivo seja atingido. São ferramentas tecnológicas que ajudam o marketing a entender o comportamento de seus consumidores.

Para se aproximar do cliente, as organizações têm utilizado sistemas de gestão do relacionamento com cliente (CRM - Customer Relationship Management), pois ajudam as empresas a administrar em sua totalidade os aspectos dos encontros com os clientes, incluindo o marketing e a publicidade, comercial, pós-vendas e programas para fidelização de cliente. (STAIR; REYNOLDS, 2011).

O CRM pode ajudar uma empresa a coletar dados dos clientes, contratá-los, educálos sobre novos produtos e vender ativamente produtos para as pessoas que já são clientes e para os novos clientes. Com frequência, o software de CRM utiliza uma 
variedade de fontes de informação, incluindo vendas das lojas de varejo, estudos, email e os hábitos de navegar na internet, para compilar os perfis abrangentes dos clientes. (...) Para se obter o máximo de benefícios, os programas de CRM devem ser adequados a cada empresa ou organização. (STAIR E REYNOLDS, 2011, p. 42).

E uma empresa que estiver lapidando todas as arestas da marca, junto com a integração de pessoas, processos e tecnologia do ponto de vista do cliente, enxergando criar valor para fidelização do cliente e aumento de rentabilidade, pode-se assim dizer que está enfim compreendendo o que é CRM. (LOBO, 2002).

Swift (2001) aponta dentre inúmeros, dois grandes benefícios do processo de implantação de CRM para a organização, a ocorrência de produtos mais convenientes e consumidores mais satisfeitos, além da demonstração de cuidado e zelo que geram uma fidelização mais eficiente, e a economia financeira uma vez que o direcionamento das verbas é melhor.

Assim, o objetivo do CRM é melhorar o processo de comunicação com o cliente certo, fazendo a oferta certa, por meio do canal certo e na hora certa. Ou seja, ser eficaz na própria tradução do termo: gerência de relacionamento com clientes. (SWIFT; 2001).

Uma das maneiras de se aplicar a gestão do relacionamento com os clientes é por meio da internet, utilizando como ferramentas as mídias e redes sociais, uma vez que, nas redes sociais os consumidores expõem suas particularidades e costumes, podendo assim a organização utilizar de CRM para atender de maneira personalizada e eficiente cada cliente, tomando menos tempo de ambos os lados (MONGE; CONTRACTOR, 2003).

\section{MARKETING DE RELACIONAMENTO E REDES SOCIAIS}

O novo conceito de marketing de relacionamento convida o cliente a se integrar nos processos decisórios de concepção de produtos (KOTLER, 2009) e já era aplicado mesmo em simples comércios de interiores ou bairros, quando o consumidor anotava suas despesas de compras em pequenos cadernos para pagamentos futuros. Essa forma de crediário próprio só era possível, graças ao conhecimento do comerciante sobre seus clientes. A confiança fazia com que não houvesse necessidade de comprovação de renda e sequer análise de crédito. Entretanto com o crescimento da economia e a mudança na cultura de compra da população essa rotina enfraqueceu e já não é comum, mesmo em pequenos centros. (MADRUGA, 2010). 
O marketing de relacionamento pode ser definido como "uma estratégia de marketing que visa construir uma relação duradoura entre cliente e fornecedor, baseada em confiança, colaboração, compromisso, parceria, investimentos e benefícios mútuos”. (LIMEIRA, 2003, apud NARCIZO, 2011, p. 70). Ainda, segundo Kotler (2009, p. 41):

as empresas inteligentes tentam desenvolver confiança e relacionamentos 'ganhaganha' a longo prazo com os consumidores, distribuidores, revendedores $\mathrm{e}$ fornecedores. Marketing de relacionamento é baseado na premissa de que os clientes importantes precisam receber atenção contínua.

Isso pode resultar em maior percentual de clientes satisfeitos, maior lealdade dos consumidores, percepção do mercado de que a empresa oferece produtos de melhor qualidade e mais lucro para o vendedor. (NARCIZO, 2011).

Contudo, atualmente a internet possibilitou novas formas de relacionamento com o consumidor (KOTLER, 2009), como por meio da utilização de mídias sociais e redes sociais. Pode-se, neste sentido, ilustrar-se essas situações com o compartilhamento de informações positivas ou negativas, relativas à organizações e seus produtos e ou serviços, por diferentes pontos de vista, em uma velocidade muito rápida, o que posiciona tais ferramentas a um patamar de importância elevado.

Os consumidores, antes da popularização da internet e mídias sociais, recebiam informações sobre empresas e produtos através da mídia televisiva ou publicidade. Tais canais podiam sofrer algum tipo de controle pelas organizações, por intermédio das relações públicas ou publicidade paga. Atualmente, o consumidor consegue verificar a reputação de determinada empresa ou produto, simplesmente acessando sua rede social e questionando usuários sobre experiências obtidas com a referida. (TORRES, 2010).

Por meio da internet, o consumidor passou a ter mais acesso a informação e, consequentemente, conseguiu obter mais conhecimento e parâmetros para questionamento, bem como liberdade para expor sua opinião sobre a qualidade e comparações sobre produtos e serviços. (CAVALLINI, 2008).

Além disso, a internet tem como uma de suas características, ser uma tecnologia social, na medida que permite que pessoas se relacionem por meio de diversas ferramentas online, ou sites de relacionamento, o que tem impactado nas empresas. (LAUDON; LAUDON, 2010). 
As empresas têm utilizado as redes sociais como um canal pelo qual ela oferece conteúdo e prestação de serviços, buscando a construção do relacionamento com os clientes e a criação de um banco de dados. (ROCHA et al., 2013).

Em uma pesquisa envolvendo 240 empresas brasileiras e seu desenvolvimento nas redes sociais, Carvalho e Murback (2014) destacaram, como motivação das empresas na utilização das redes sociais, o estreitamento do relacionamento com os clientes e a otimização das ações de marketing e venda.

Nesse sentido, evidências apontam que a intensidade de acesso (tempo on line) às mídias sociais influência na decisão de compra dos usuários, bem como a credibilidade e a importância das opiniões referentes à determinada marca/empresa. (MACLENNAN et al., 2014). Além disso, Damacena, Petroll e Vontobel (2015) apontaram que o conteúdo criado em redes sociais pelas empresas, especificamente no Facebook, influencia diretamente a percepção do consumidor sobre a atitude em relação à marca e valor da marca, afetando positivamente na intenção de compra, demonstrando assim que a comunicação de marca ainda é controlada e administrada pelas empresas.

Contudo, a capacidade de uma empresa de estar presente em todas as redes sociais, tal fato exige uma compreensão e atenção para as diferenças e utilidades de cada uma das mídias, para que seu uso seja objetivo e otimizado.

\subsection{Redes sociais}

A evolução da comunicação em massa, que passou dos meios impressos aos eletrônicos e, mais recentemente, aos digitais, fez com que a comunicação organizacional absorvesse uma lista de ferramentas que vai da intranet até os blogs, microblogs chats e redes sociais. Com a necessidade de agilidade nas comunicações com seus diversos públicos, as organizações estão enxergando na comunicação digital uma opção para diálogo. (TERRA, 2011).

Conforme afirma Rocco Junior (2006), a última geração de mídia eletrônica em massa, que opera com a nova estrutura da informação, briga cada dia mais com os meios de mídia tradicional, utilizando recursos que variam de som a imagem, são exemplos que ilustram essa tendência. Além disso,

a esfera da conversação mundial se ampliou, como ser comprovado com a expansão de sistemas e ferramentas de comunicação como blogs, wikis, podcasting, softwares sociais [...] ou os novos sistemas de 'mobile social networking', permitindo a troca 
de informação entre pessoas e comunidades em mobilidade, via dispositivos portáteis de acesso sem fio às redes. (LEMOS, 2010, p.25)

Redes sociais digitais são serviços fornecidos em rede que permitem que indivíduos construam um perfil público dentro de um sistema limitado; gerenciem uma lista de outros usuários com quem eles interagem; e vejam e cruzem sua lista de conexões e aquelas feitas por outros dentro do sistema. (BOYD; ELLISON, 2008). É um conjunto de dois elementos: atores sociais (pessoas, instituições ou grupos) e suas conexões (interações ou laços sociais). Vale lembrar que fora do meio eletrônico, a comunidade também participa de redes sociais como, igrejas, salas de aula, clubes de futebol e empresas. (RECUERO, 2009).

A primeira rede social online, foi criada em 1997 chamada de SixDegrees, tinha como características específicas para ser uma rede social, conforme denominações, perfis dos outros e listas de amigos. Acabou saindo do mercado em 2001. Seguindo o sucesso inicial da SixDegrees, inúmeras outras redes surgiram como: AsianAvenue (1997), Black Planet (1999), LiveJournal (1999), MiGente (2000), Ryze.com (2001), Friendster (2002), dentre outros, onde se descaram MySpace (2003), Facebook (2004), Orkut (2004) e Twitter (2006). (MONGE; CONTRACTOR, 2003).

As empresas têm cada dia mais utilizado as ferramentas disponíveis pelas redes sociais, para se comunicar com seus clientes ou seu público alvo. Da mesma maneira, os clubes de futebol utilizam essas ferramentas com a intenção de estreitar o relacionamento com seus torcedores.

\footnotetext{
As redes sociais na internet surgem, nesse contexto, como um cenário fértil para se pensar na midiatização empresarial e nas tensões decorrentes desse fenômeno. Isso porque, ao mesmo tempo em que representam novas chances de visibilidade para as organizações se legitimarem diante de seus públicos, essas novas mídias são uma ameaça para os mecanismos tradicionais de gestão e reputação e de comunicação em contextos organizacionais. (MOL, 2012, p. 266).
}

A partir desse conhecimento sobre as redes sociais e seus reflexos para a organização, os departamentos de comunicação dos clubes de futebol devem estar atentos aos prós e contras da exposição em uma mídia tão participativa como as digitais, como explica (MOL, 2012, p. 270): "ao mesmo tempo em que a organização busca se mostrar, se expor, enfim, tornar-se visível diante do outro para ser reconhecida, vive o dilema de ter de controlar como essa visibilidade se dará". 


\section{METODOLOGIA}

O presente artigo constituiu um estudo de caso que trata a interação entre o clube de futebol Sport Club Corinthians Paulista e seus torcedores através de redes sociais eletrônicas, utilizando de abordagem descritiva e mista, qualitativa e qantitativa, com utilização de entrevista e questionários para levantamento de dados.

A pesquisa descritiva é um estudo de análise, registro e interpretação dos fatos do mundo físico sem a interferência do pesquisador (BARROS; E LEHFELD, 2007). O estudo de caso é uma metodologia utilizada nas ciências médicas e sociais, consistindo em um estudo profundo e exaustivo de um específico objeto ou de uma quantidade pequena e limitada, de maneira que permita o detalhamento e conhecimento amplo do assunto pesquisado, tarefa impossível mediante a outros delineamentos já considerados. (GIL, 2002).

O método misto utilizado na pesquisa, envolveu procedimentos concomitantes, no qual "o pesquisador faz a convergência de dados quantiativos e qualitativos a fim de obter uma análise mais ampla do problema de pequisa, [...] coleta as duas formas de dados ao mesmo tempo durante o estudo e depois integra as informações nas interpretações dos resultados gerais." (CRESWELL, 2007, p. 33).

Baseada nesse método, a coleta de dados envolveu a utilização de questionários e entrevistas. O questionário foi um conjunto de questões, articuladas entre si, com objetivo de levantar informações escritas pelos entrevistados, com foco na obtenção das opiniões sobre o assunto. (SEVERINO, 2007).

A entrevista é uma técnica de coleta de informações sobre um determinado assunto, coletadas diretamente ou indiretamente pelo pesquisador, diretamente aos sujeitos pesquisados. Tal técnica visa, que o pesquisador aprenda o que os sujeitos pesquisados, pensam, sabem, representam, fazem ou argumentam. (SEVERINO, 2007). Especificamente, a entrevista semi-estruturada, tipo utilizado nesta pesquisa foca-se em um assunto sobre o qual é confeccionado um roteiro com perguntas principais, complementadas por outras questões inerentes as circunstancias momentâneas à entrevista. (MANZINI, 1990/1991).

No que diz respeito aos procedimentos, a pesquisa foi dividida em duas etapas: (1) questionário respondido por 801 torcedores utilizando a ferramenta de formulários do Google, enviados por e-mail, whatsapp, mensagens sms, além do convite fora das redes sociais, no site "meu timão", maior site da torcida do Corinthians, buscando com isso a averiguação da 
porcentagem de torcedores que utilizam os canais de comunicação online; e (2) entrevista semiestruturada com o responsável pelo departamento de comunicação do Sport Club Corinthians Paulista.

Para análise dos dados coletados com o questionário, quantitativos, foi utilizado o método de análise estatística descritiva, que segundo Reis (1998), se preocupa em descrever os dados, sintetizando uma série de valores de mesma natureza, permitindo dessa forma que se tenha uma visão global da variação desses valores, organizando e descrevendo os dados de três maneiras: por meio de tabelas, de gráficos e de medidas descritivas. E a entrevista foi análisada por meio de análise temática, que visa identificar temas que surgem na fala dos entrevistados (BARDIN, 2010).

\section{APRESENTAÇÃO E ANÁLISE DOS DADOS}

5.1. Perfil e utilização de redes sociais pelos torcedores

No estudo foram obtidos 801 questionários respondidos, por meio de contatos feitos através da ferramenta do Google, enviados por e-mail, whatsapp, mensagens sms, e também convidados a participar em um ambiente fora das redes sociais, no site "meutimão", que é o maior site da torcida do Corinthians.

A pesquisa foi feita com uma amostra por adesão e seu perfil apresentou predominância de pessoas jovens do sexo masculino (Figura 1), com faixa de renda entre $2 \mathrm{e}$ 10 salários mínimos, com grau de instrução entre ensino médio compelto e superior completo (Figura 2), principalmente representantes da região sudeste do Brasil, com relativa alta frequência de interação com o clube via redes sociais (Figura 3). 
Figura 1: Dados relativos a Sexo e Idade dos torcedores.
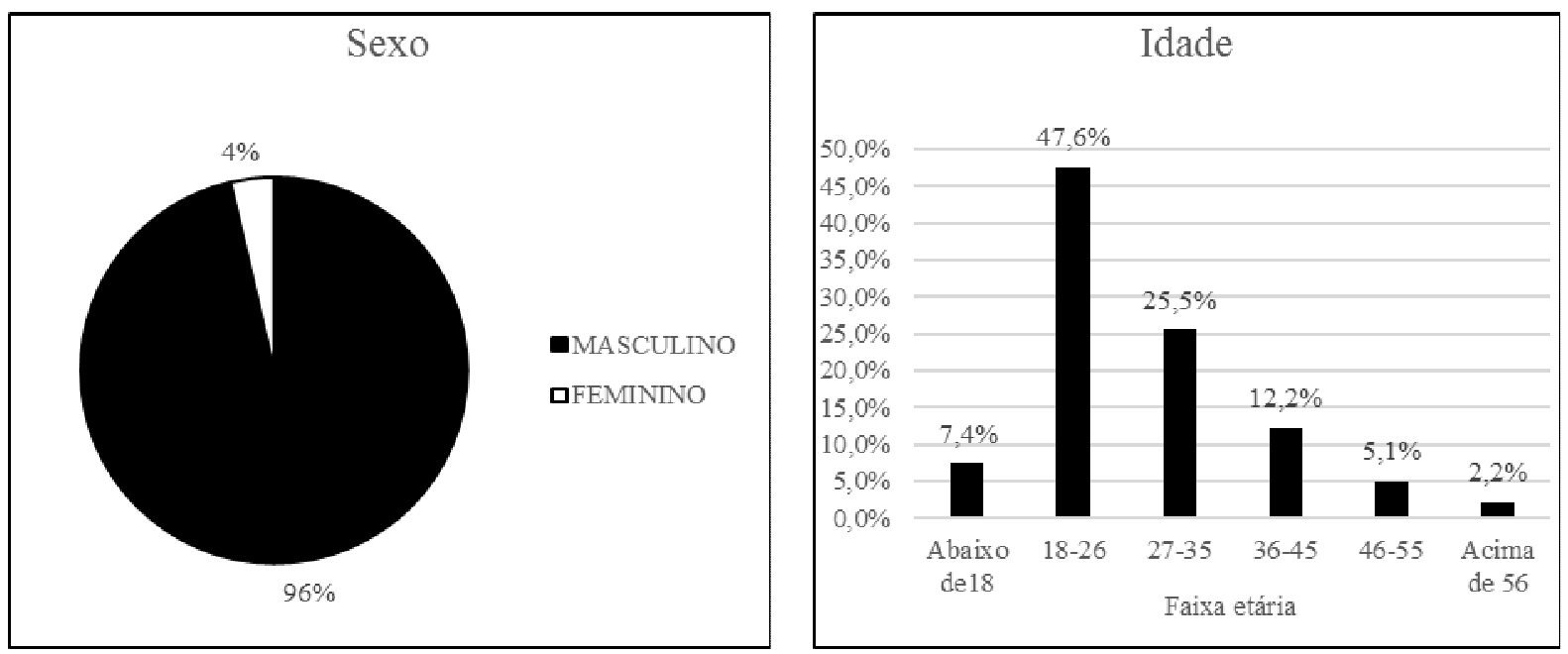

Fonte: Dados da pesquisa.

Figura 2: Dados de renda e escolaridade dos torcedores.
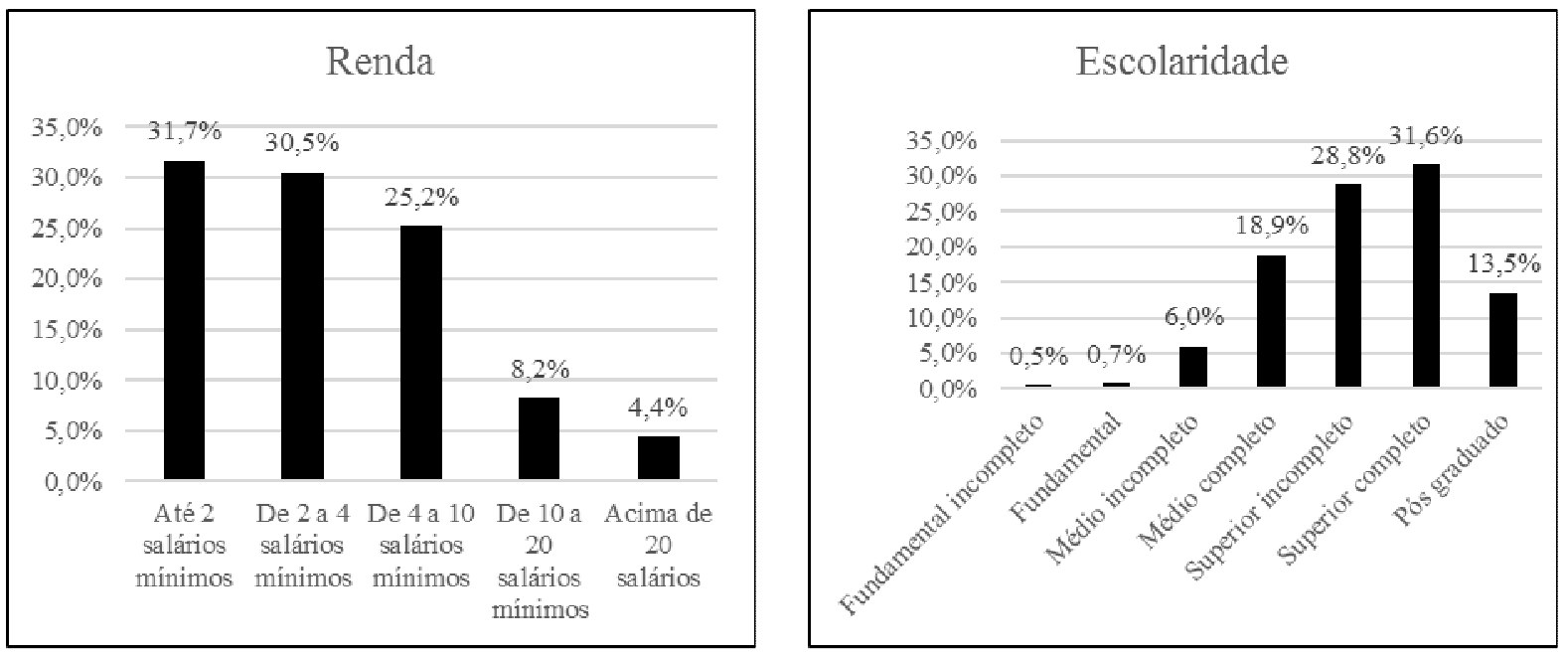

Fonte: Dados da pesquisa.

Figura 3: Região dos torcedores e sua frequência de interação com o clube nas redes sociais.
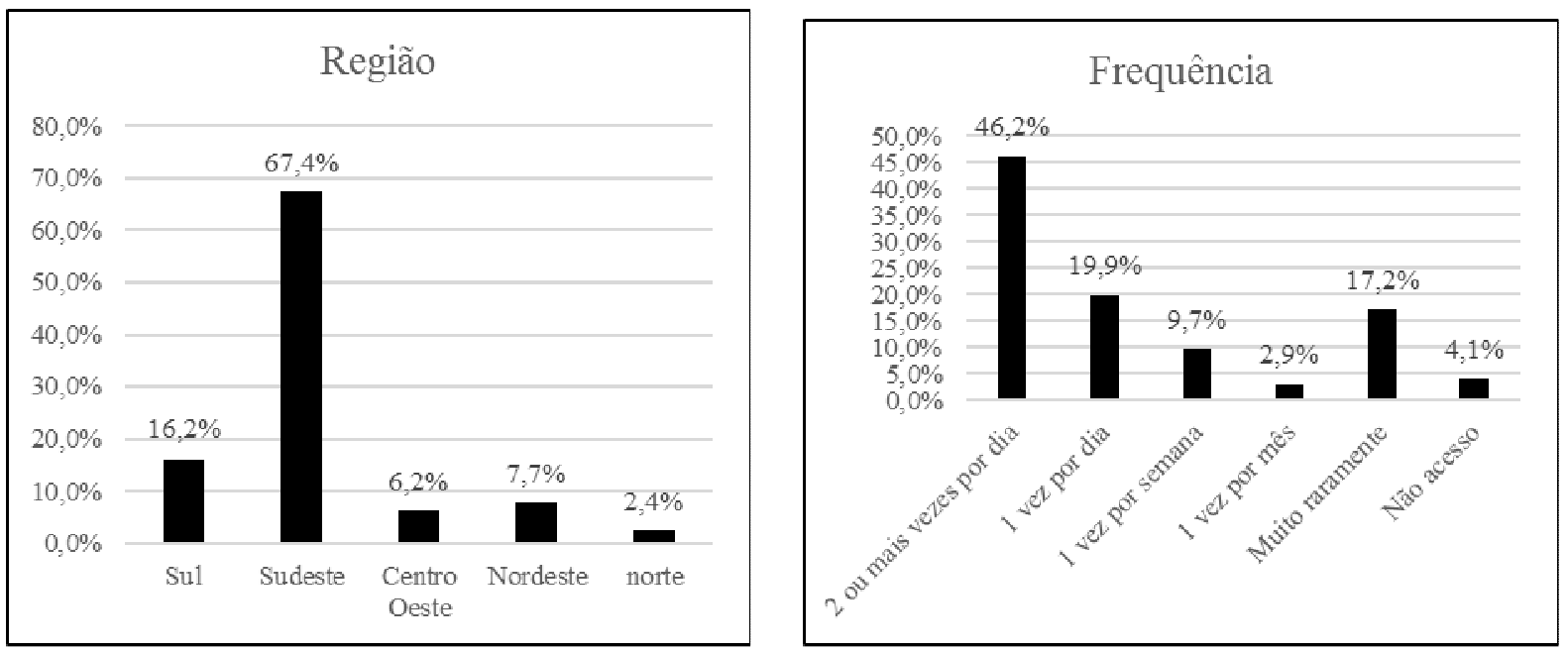

ReFAE - Revista da Faculdade de Administração e Economia, v. 9, n. 1, p. 214-234, 2018 
Fonte: Dados da pesquisa.

Uma vez estabelecido o perfil dos respondentes, levantou-se que a rede social que os torcedores mais utilizam de maneira geral e preferem utilizar como meio de interação com o clube (Figuras 4 e 5) é o Facebook, seguida pelo Youtube, sendo o Twitter a rede social relativamente menos utilizadas de maneira geral pelos torcedores.

Figura 4: Utilização das redes sociais de maneira geral.

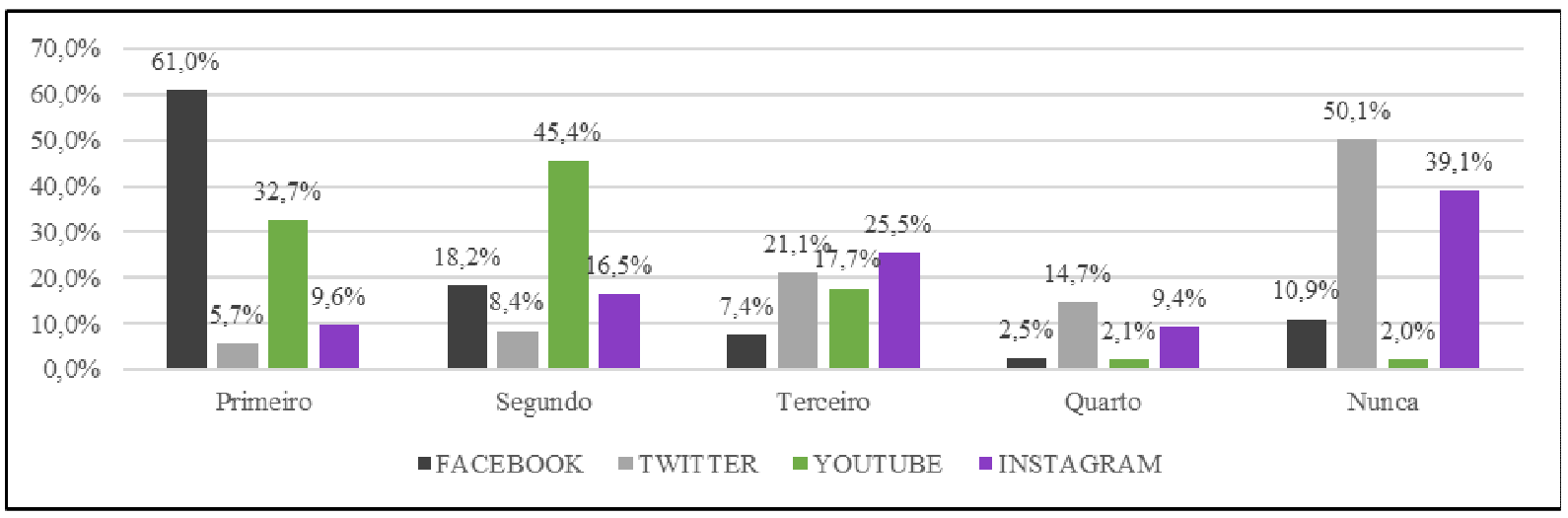

Fonte: Elaborado pelo autor.

Figura 5: Utilização das redes sociais para interação com o SCCP.

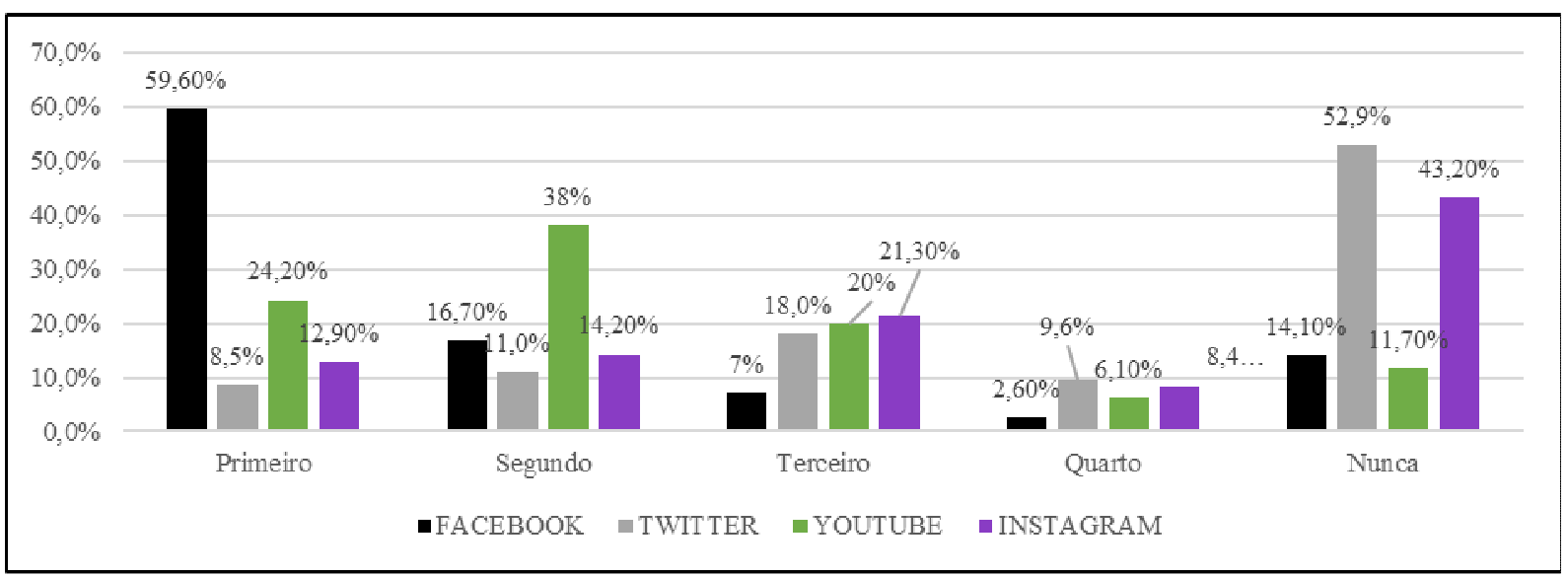

Fonte: Elaborado pelo autor.

Abordou-se ainda quanto a opinião dos respondentes sobre em qual rede social o SCCP se aproxima mais de seus torcedores, e em qual os torcedores se aproximam mais do clube. Se destacaram nesse quesito o Facebook apareceu como a rede social que mais aproxima o clube dos seus torcedores, seguido pelo Twitter (Figuras 6 e 7). 
Figura 6: Aproximação SCCP x torcedores.

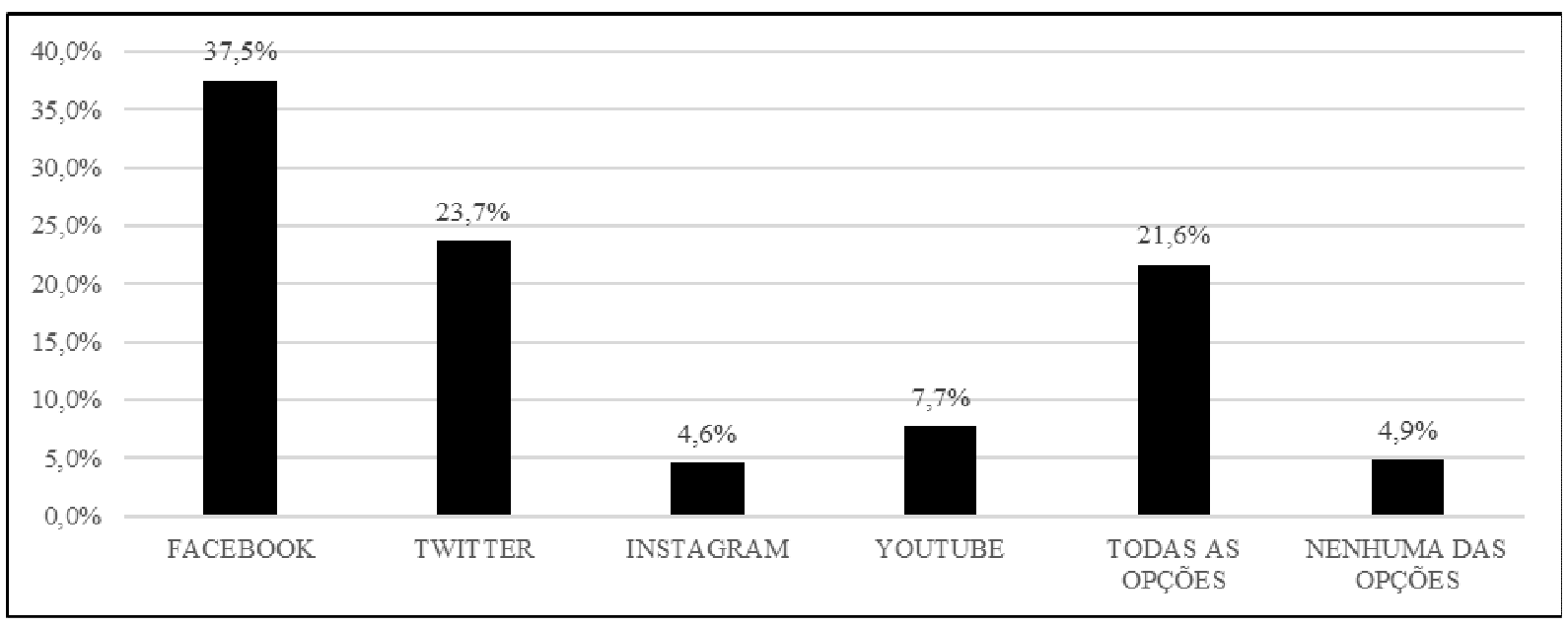

Fonte: Elaborado pelo autor.

Figura 7: Aproximação torcedores x SCCP.

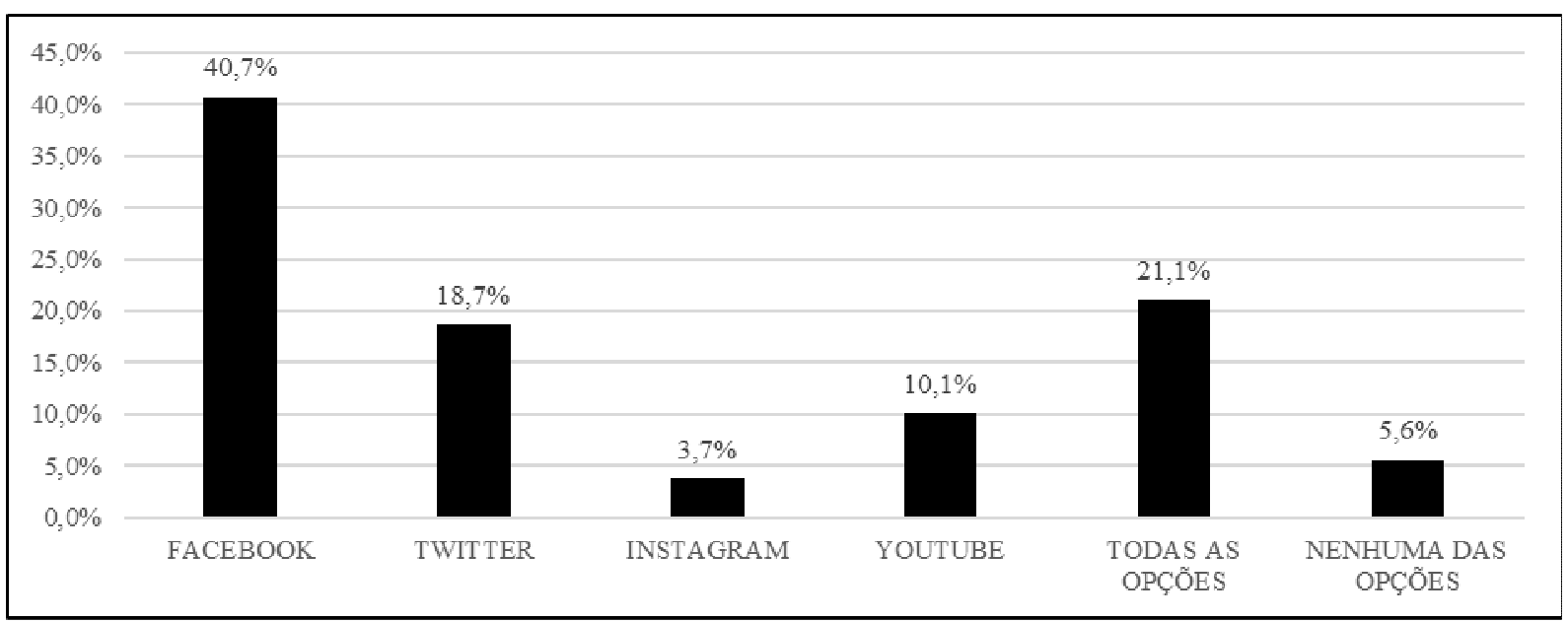

Fonte: Elaborado pelo autor.

Por fim, levantou-se se os torcedores estavam satisfeitos com as informações fornecidas pelo clube nas redes sociais, no sentido de se elas são suficientes para mantê-los atualizados quanto ao dia a dia do clube, e também, se a possibilidade de o clube encerrar suas atividades nas redes sociais causaria algum incômodo aos entrevistados, sendo esta questão exposta na (Figura 8). 
Figura 8: Satisfação quanto as informações e sua reação quanto à ausência do clube nas redeso sociais.
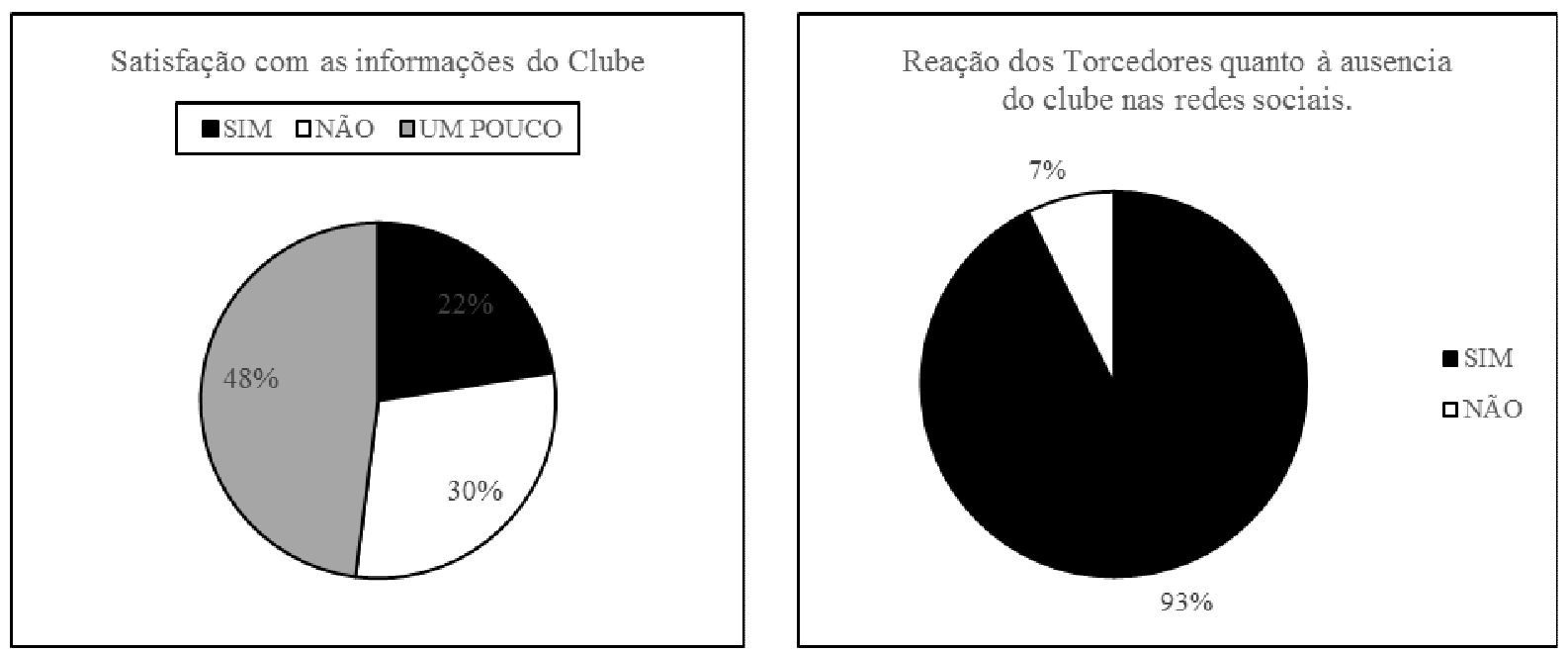

Fonte: Elaborado pelo autor.

Verifica-se na Figura 8 que $47.9 \%$ dos respondentes consideram que as informações postadas pelo clube nas redes sociais são pouco suficientes para mantê-los informados sobre o dia a dia do time, $29.6 \%$ consideram as postagens insuficientes e $22.5 \%$ estão satisfeitos e que 92.6\% dos respondentes enxergariam de forma negativa o encerramento das atividades do clube nas redes sociais.

Foi lançada aos respondentes, ao final do questionário, uma questão qualitativa, visando levantar o motivo pelo qual os torcedores acompanham o clube nas redes sociais, e dentre as respostas obtidas foi possível identificar temas, segundo os quais os torcedores o faziam por: amor ao clube, fanatismo, informações e notícias, ser um novo meio de comunicação, diversão e confiabilidade nas informações, se destaque os temas 'amor ao clube' e 'fanatismo'. Dos 801 entrevistados, 166 não responderam essa questão e 11 responderam não seguir o clube ou não possuírem redes sociais.

\subsection{Perfil e utilização das redes sociais pelo Corinthians}

Fundado dia 01 de setembro de 1910, sob a luz de um lampião no bairro do Bom Retiro, o Sport Club Corinthians Paulista é um dos times mais tradicionais do Brasil. Diaféria (1992) cita que o nome do clube foi escolhido pela influência do time inglês que passava pelo Brasil em 1910, o primeiro presidente eleito, o alfaiate Miguel Battaglia em suas primeiras afirmações citou: "O Corinthians será o time do povo, e o povo é quem fará o time.”. 
Sediado em São Paulo capital do estado, o clube além de ser mundialmente reconhecido pelo time de futebol, também representa diversas outras modalidades como: Futsal, Basquete, Natação, Bocha, Futebol Americano, Judô dentre outros. Assim como uma empresa, o clube possui departamentos para sua gestão, um deles é o departamento de comunicação.

Assim, foi realizada uma entrevista com o gerente de conteúdo digital do clube, responsável pelo departamento de comunicação há 5 anos, tendo participado desde o início da utilização das redes sociais no clube.

A função desse departamento embora não exclusiva, atualmente é administrar os canais de comunicação digital e contas nas mídias e redes sociais conforme citado pelo gerente de marketing do clube na entrevista.

De acordo com o entrevistado, quanto às redes sociais em que o clube está presente se destacam, por ordem de importância, o Facebook, o Twitter, o Instragram, o YouTube e o Google Plus. Cada rede social se encaixa em um objetivo de utilização, cada uma delas recebendo conteúdo em linguagens diferentes.

Destas cinco redes sociais o entrevistado destacou duas, o Facebook e o Twitter. O Facebook se destaca, segundo o entrevistado, por propiciar o alcance de maior número de pessoas, devido ao volume de torcedores presentes nessa rede social e a maior diversidade na faixa etária que esta rede apresenta. E o Twitter, por exemplo, é uma rede diretamente relacionada às atividades do momento atual, onde se discute os assuntos presentes na televisão, aberta ou fechada.

Foi também citado pelo entrevistado, que o principal objetivo do Corinthians na utilização das mídias sociais é reforçar, fortalecer e evidenciar os valores da marca perante o público. O conteúdo postado pelo departamento de comunicação é frequentemente monitorado com relação à sua aceitação e a interação do público, para que seja atualizado sempre que houver a necessidade e a marca continue participativa, atuante e em evidência.

As mídias sociais também são destinadas à interação com os torcedores, que abrange a recepção das críticas, elogios e sugestões. O entrevistado explicou que o time não dispõe de um departamento destinado exclusivamente à interação diária com os torcedores nas redes sociais e que esta atividade é realizada à medida que surge disponibilidade de tempo, utilizando preferencialmente o Twitter, por apresentar maior dinâmica nesta interação com o torcedor e se encaixa melhor no cotidiano das tarefas do clube. É destacado que, mesmo quando não é possível a interação com o público, os conteúdos discutidos nas redes sociais sempre são acompanhados e, na medida do possível, atendidos.

ReFAE - Revista da Faculdade de Administração e Economia, v. 9, n. 1, p. 214-234, 2018 
Para o entrevistado, os resultados dessas iniciativas nas redes sociais refletem na visibilidade que a marca recebe e já começa a apresentar alguma lucratividade financeira para o clube, de modo que o próprio departamento é sustentado por esta lucratividade, e que espera um aumento significativo dentro de um prazo de 4 a 5 anos.

De acordo com o entrevistado, nota-se que existe uma forte tendência no aumento da proporção de pessoas que tem acesso ao universo digital e, consequentemente, a receita gerada por esses meios tende a aumentar, destacando ainda mais a importância das redes sociais para a saúde financeira do clube.

Por fim, o entrevistado vê grande importância no uso das mídias sociais para a vida do clube, pois elas exercem a função de um termômetro, de onde é possível ter acesso à visibilidade do time perante os torcedores, fãs e sócios, maiores formadores de opinião e influenciadores em relação à imagem do time.

\subsection{Análise dos dados.}

O perfil mais representado nesta pesquisa, por adesão, foi de pessoas, em sua maioria, jovens, do sexo masculino, com faixa de renda entre 2 e 10 salários mínimos, com grau de instrução entre ensino médio compelto e superior completo, principalmente representantes da região sudeste do Brasil, com relativa alta frequência de interação com o clube via redes sociais.

Das quatro redes sociais pesquisadas, o Facebook e o Youtube foram as mais notadas e populares entre os torcedores, e foram também as ferramentas com maior número de usuários. Este dado coincide com a informação passada pelo responsável de comunicação do clube como a rede à que se destina maior atenção pelo SCCP.

Apesar do Facebook ter sido apontado pelo entrevistado como foco, devido ao alcance à todas as faixas etárias, os resultados obtidos mostraram que o público que a utiliza é predominantemente jovem.

Além disso, o Facebook junto com o Twitter foram considerados as redes sociais que permitem o público se aproximar mais do clube, bem como ao clube se aproximar dos torcedores. Contudo, o Twitter é a rede social relativamente menos utilizada pelos torcedores.

Na entrevista, as redes sociais têm importância destacada por permitir a interação com os torcedores por meio do acesso às críticas e sugestões. Cerca de 50\% dos torcedores acompanha o clube pelo menos duas vezes ao dia nas redes sociais, apresentando uma 
demanda intensa de conteúdo por parte do clube, em contrapartida, cerca de $50 \%$ dos respondentes defendem que as informações postadas pelo clube são insuficientes.

Por fim, apesar de um alto número de torcedores acharem insuficientes as informações passadas pelo clube, $93 \%$ dos torcedores achariam negativa a saída do clube das redes sociais, corroborando a informação passada pelo entrevistado do clube quanto sua dedicação em estar presente e ativa nas redes sociais e reforçar o valor da marca, com constante monitoramento e renovação dos conteúdos postados.

Destaca-se que o principal ponto do artigo, no que tange a relação entre CRM, não como ferramenta tecnológica, mas como filosofia de gestão, é viabilizada, como observado no caso estudado, principalemente pelas ferramentas Facebook e Twitter, o que é consoante com a literatura, no que tange à utilização dessas redes sociais na interação com o cliente.

O Facebook permite uma aproximação entre cliente e organização, na contribuição de algum projeto em execução, ou ainda, melhora a imagem e credibilidade perante os clientes. Um outro ponto positivo na rede, é a possibilidade de atingir um público específico com sua página, esta criada de forma gratuita, pode ser rentabilizada através de anúncios pagos e links patrocinados, gerando assim uma forma de propaganda de alta abrangência e de custo relativamente baixo. (CARVALHO, 2011). Assim, as empresas utilizam as FanPages do Facebook, uma página com as informações da marca, como principais ferramentas de marketing digital. (BRITO; MALHEIROS, 2013).

E o Twitter, como uma ferramenta de comunicação e microblogging, possui uma ferramenta chamada de Trending Topics (Tópicos do Momento), onde em uma escala é apontado os assuntos mais discutidos no mundo, ou em determinada região ou país. Essa ferramenta é interessante para que organizações e empresas, possam medir o que está sendo publicado a seu respeito, podendo interagir com os autores das postagens. É comum encontrar perfis de empresas, que até mesmo brincam com seus consumidores, passando uma imagem de modernidade e aproximação. (BRITO; MALHEIROS, 2013). Contudo, essa ferramenta deve ser considerada com mais cuidado, uma vez que não aparenta ser tão utilizada quanto as demais.

\section{CONCLUSÃO}

As redes sociais são ferramentas de comunicação importantes quando abordadas a partir da perspectiva de CRM de uma empresa ou organização. Tais ferramentas permitem se 
aproximar de seu público de maneira mais espontânea e menos formal, captando assim muitas vezes as verdadeiras opiniões e necessidades. O SCCP utiliza as redes sociais como ferramenta para reforçar sua marca junto ao seu público e captando por meio delas informações e preferências dos torcedores. Dessa forma promovem o conteúdo postado em seus perfis monitorando a aceitação e atualizando constantemente a postagens.

O Facebook é a rede social apontada como a mais utilizada e difundida na interação entre o clube e os torcedores, em que as postagens são frequentes e o número de usuário é maior quando comparado às demais redes sociais. Este resultado é reforçado por Carvalho e Murback (2014), que verificaram dentre 240 empresas, que 97.2\% apresentam maior atividade no Facebook.

Destacou-se o Twitter, não como a feramenta mais utilizada de maneira geral pelos torcedores, mas a segunda ferramenta mais utilizada para a interação do clube e os torcedores. O que levaria a organização a considerar o papel dessa ferramenta na gestão do relacionamento com os clientes.

Observou-se, por fim, que, em uma dimensão qualitativa, a principal motivação dos torcedores em acompanhar o Corinthians nas redes sociais, de acordo com a maior parte dos torcedores pesquisados, é o amor ao time e a vontade de manterem-se atualizados quanto às notícias do time, existindo grande entusiasmo quanto à presença ativa do clube.

Em contrapartida, notou-se também significativa insatisfação quanto ao nível de interação efetiva com o público, mostrando que a o clube poderia melhorar seu conceito e cultura de CRM, uma vez que o conceito é uma via de mãos duplas de comunicação. O clube utiliza os dados para monitorar a aceitação das postagens, conforme citado pelo gerente de marketing, no entanto a torcida não consegue enxergar bem o retorno de suas comunicações. O que é coerente com a questão de as mídias sociais serem um canal de mão dupla.

Assim, entendeu-se que o clube tem uma boa utilização das redes sociais na perspectiva do CRM, precisando de algumas adequações no que tange, ao público em relação às ferramentas utilizadas e na sua participação ativa na interação, que pode ser melhorada.

Dentre as limitações da pesquisa, destaca-se a impossibilidade de realização da entrevista com o responsável do departamento de comunicação do clube pessoalmente, e a indisponibilidade de captação de dados fora do meio online, fato que poderia aumentar o tamanho da amostra e também agregar maior diversidade ao perfil dos entrevistados.

Sugere-se pesquisas futuras sobre a cultura de CRM em clubes de futebol utilizando as mídias sociais, uma vez que o torcedor também é visto como um consumidor da marca. Um estudo mais elaborado sobre a percepção desse canal e ações realizadas através dos dados 
coletados por essas mídias, relacionando-os diretamente à questão do fortalecimento da marca. Bem como as potencialidades de cada mídia social e como podem limitar ou ampliar ações de relacionamento com o cliente.

\section{REFERÊNCIAS}

BARROS, A. J. S.; LEHFELD, N. A. S. Fundamentos de Metodologia Cientifica. 3.ed. São Paulo: Prentice-Hall, 2007.

BARDIN, L. Análise de Conteúdo. São Paulo: Edições 70, 2011.

BOYD, D.; ELLISON, N, B. (2008). Social network sites: Definition, history, and scholarship. Journal of Computer-Mediated Communication, 13(1), 516-529. Disponível em: $<$ http://onlinelibrary.wiley.com/store/10.1111/j.1083-6101.2008.00408.x/asset/j.10836101.2008.00408.x.pdf?v=1\&t=iykrcr9r\&s=897351b91479a1a0f22c6843190d4d2f1d93bd59 $>$ Acessado em: 30/01/2017 - 22:05 hrs.

BRITO, D. S.; MALHEIROS, T, C. A importância das mídias sociais e das ferramentas gratuitas do google no mercado de e-commerce no Brasil para microempresas. C@LEA Revista Cadernos de Aulas do LEA, Ilhéus, n. 2, p. 1 - 18, nov. 2013.

CARVALHO, B. M. As redes sociais mais usadas pelas empresas; Universidade Candido Mendes - Agosto, 2011. Disponível em:

$<$ http://www.avm.edu.br/docpdf/monografias_publicadas/r200453.pdf>

CARVALHO, V. O.; MURBACK, F. G. R. Estudo da utilização das redes sociais digitais nas empresas brasileiras. Gestão e Conhecimento - Revista do Curso de Administração / PUC Minas.

CAVALLINI, R. O marketing depois de amanhã: explorando novas tecnologias para revolucionar a comunicação. - 2. Ed. - São Paulo. Ed. do Autor, 2008.

CRESWELL, J. W. Métodos qualitativo, quantitativo e misto. 2 ed. Porto Alegre: Artmed, 2007.

DAMACENA, C.; PETROLL, M. L. M.; VONTOBEL, J. K. Os efeitos da comunicação nas mídias sociais sobre o consumidor: uma replicação do estudo de Schivinski e Dabrowski (2014). Revista Gestão e Tecnologia, Pedro Leopoldo, v. 15, n. 2, p. 135-160, mai./ago. 2015 .

DIAFÉRIA, L. Coração Corinthiano - Grandes Clubes do Futebol Brasileiro e Seus Maiores ídolos - Volume II - Corinthians. Fundação Nestlé de Cultura - Editora Bisordi - 1992.

GIL, A, C. Como elaborar projetos de pesquisas - 4. Ed - São Paulo: Atlas, 2002. 
GORDON, R. S.; GORDON, R, J. Sistemas de informação: Uma abordagem Gerencial. Três ed. Rio de Janeiro: LTC, 2011.

KOTLER, P. Marketing para o século XXI: como criar, conquistar e dominar mercados. São Paulo: Ediouro, 2009.

LAUDON, K.; LAUDON, J. Sistemas de Informação Gerenciais. Tradução 9. Ed. - São Paulo: Pearson Prentice Hall, 2010.

LEMOS, A. O futuro da internet: em direção a uma ciberdemocracia - São Paulo: Paulus, 2010.

LIMEIRA, T. M. V. Administração das comunicações em marketing. In: DIAS, S. R. Gestão de marketing. São Paulo: Saraiva, 2003. p. 7, 301

LOBO, A. Marketing de relacionamento. São Paulo: Seminários SSJ, 2002.

MACLENNAN, M. L. F. et al. Associação entre intensidade de uso de midias sociais, credibilidade e decisão de compra. Revista de Gestão e Tecnologia, Florianópolis, SC, v. 4, n. 2, p. 65-77, jul./dez. 2014.

MADRUGA, R. Guia de implementação de marketing de relacionamento e CRM. 2. ed. São Paulo: Atlas, 2010.

MANZINI, E. J. A entrevista na pesquisa social. Didática, São Paulo, v. 26/27, p. 149$158,1990 / 1991$.

MÁXIMO, J. Memórias do futebol brasileiro. Estudos Avançados, São Paulo, v. 13, n. 37 , p.179 - 88, set. / dez. 1999.

MONGE, P. R.; CONTRACTOR, N. Theories of communication net-works. New York: Oxford University Press, 2003. Trad. MONTENEGRO, L. M.

MOL, V. B. Midiatização empresarial: visibilidade versus controle nas redes sociais na internet. Redes Sociais, Comunicação, Organizações. São Caetano do Sul/SP: Ed. Difusão. Editora Difusão. Série Pensamento e Prática, v. 5, 1ª edição. Abril, 2012.

NARCIZO, R. A. M. Marketing de relacionamento: Um diferencial das Lojas Lafibrunn Infanto Juvenil - in Perspectivas Online. Vol. 5 N.17. 2011.

O'BRIEN, J. A. Sistemas de informação e as decisões gerenciais na era da Internet. Trad. de Célio Knipel Moreira e Cid Knipel Moreira. 2. ed. São Paulo: Saraiva, 2004. 431p.

RECUERO, R. Redes sociais na internet. Porto Alegre: Sulina, 2009. (Coleção Cibercultura) $191 \mathrm{p}$.

REIS, E. Estatística descritiva. Lisboa: Silabo, ed. 4, 1998. 


\section{RELATÓRIO FINAL DO PLANO DE MODERNIZAÇÃO DO FUTEBOL}

BRASILEIRO. Rio de Janeiro: Fundação Getúlio Vargas e Confederação Brasileira de Futebol, 2000.

ROCCO JÚNIOR, A. J. O Gol por um clique: uma incursão ao universo da cultura do torcedor de futebol no ciberespaço. 2006. Doutorado em Comunicação e Semiótica Pontifícia Universidade Católica de São Paulo, São Paulo, 2006.

ROCHA, T. V. et al. Estudo exploratório sobre o uso das redes sociais na construção do relacionamento com os clientes. Revista Brasileira de Gestão de Negócios, RGBN, São Paulo, v. 15, n. 47, p. 262-282, abr./jun. 2013.

SCCP - Sport Club Corinthians Paulista. Disponível em:

$<$ http://www.corinthians.com.br/clube/historia> - acesso 15-07-16 - 14:30 hrs.

SEVERINO, A. J. Metodologia do trabalho científico. 23. Ed. - São Paulo: Cortez, 2007.

STAIR, R. M.; REYNOLDS, G. W. Princípios de sistemas de informação. Tradução 9. Ed. - São Paulo: Cengage Learning, 2011.

SWIFT, R. CRM: Customer Relationship Management, o revolucionário marketing de relacionamento com o cliente. Rio de Janeiro: Prentice Hall, 2001.

TERRA, C. F. Mídias sociais...e agora? Tudo o que você precisa saber para implementar um projeto de mídias sociais. São Caetano do Sul: Difusão Editora; Rio de Janeiro: Editora Senac Rio, 2011.

TORRES, C. Guia prático de marketing na internet para pequenas empresas, 2010. Acessado em Julho de 2016.

TRIVIÑOS, A. N. S. Introdução à pesquisa em ciências sociais: a pesquisa qualitativa em educação. São Paulo: Atlas, 1987.

URDAN, A. T.; URDAN, F. T. Marketing Estratégico No Brasil - Teoria e Aplicações. São Paulo, Atlas, 2010. 